\title{
La integración vocacional a la luz de la Sagrada Escritura
}

La vida consagrada conduce a una integración, a un estado de consolación perenne, en el que la persona se siente realizada en el sentido de su vida y va alcanzando la meta de su entrega, su propia salvación (cf. 1 Pd 1,9) y su autotrascendencia en Dios. La fuente de esta consolación reside en la misma realidad de la llamada y, como no existe momento en el que el hombre no se sienta llamado por Dios (cf. 1 Ts 2,$12 ; 5,24$ ), en ninguna situación puede sentirse excluido de la posibilidad de gozar del consuelo de Dios (2 Cor 1,3ss); por otra parte, como la llamada es fruto del amor de Dios, así lo es también su consuelo ( 2 Tes 2,17), que está implícitamente conectado con la fidelidad de Dios y de su llamada (1 Tes 5,$24 ; 1$ Cor $1,9 \mathrm{cp}$. Rm 11,25), una llamada a la Compañía de su Hijo Jesús (1 Cor 1,9), de forma que la misma llamada es la que dinamiza la fidelidad del hombre y le capacita para responder hasta el final $(2$ Ts 1,11$)$ y poder de este modo gozar de la felicidad de los llamados a la Cena del Cordero (Ap 19,9) y de la dicha de los invitados a participar en su alegría, porque han respondido auténticamente a las condiciones de su llamada (Mt 22,12). Se trata, pues, de un consuelo primariamente dinamizado por la llamada de Dios y por su elección al ministerio (1 Ts 2,3).

Aquí radica también otra fuente de la integración personal en la vida vocacional, que es la misma misión y su ejercicio, ya que junto con la misión va siempre la promesa de la asistencia divina, que es fuente de consuelo para el llamado. Ya en el caso de Abraham, el gozo de la vocación (Gn 12, 1-3.7) corresponde también la bendición del Señor por la obediencia a ella (Dt 10,7 Sl 37,26), como aparece también en otras grandes figuras vocacionales del A.T.: Moisés (Ex 3,4; 4,15), Josué (Jos 1,5s. Dt 31,23), Gedeón (Jc 6,16), Saúl (1 Sm 9,21; 10,7), David (1 Sm 16,18; 17,37; 18,12.14,28;20,13; 2 Sm 5,10; $7,9)$ y Jeremías $(J r 1,8.19)$. También María $(\operatorname{Lc} 1,28)$ y Jesús de Nazaret sobre 
todo aparece en el N.T. bajo la continua asistencia de su Padre en la misión $(\mathrm{Jn} 8,29)$ y él mismo promete la suya a todos sus enviados (Mt 28,20b).

Junto a la promesa de asistencia, va con frecuencia una señal que confirma la presencia de Dios al lado de sus enviados y que es también prenda de consuelo, como en el caso de Gedeón $(J c 6,17)$ y de Natanael $(J n$ 1,48) y también en el de Elías, quien se siente fortalecido por el alimento de Dios (1 Ry 19,5-8), y en el de Jesús, a quien un ángel conforta en sus momentos difíciles (Lc 22,43 cp. Mc 1,13b cp. et. Mt 26,53). En el caso de Moisés la señal viene a desvanecer una debilidad en la fe y en la confianza (Ex 4,6-9), que luego le permitirá presentarse también como profeta del Señor ante su pueblo (Ex 4,17 ) con un nuevo ímpetu, como le acontece también a Ezequiel, quien, si se siente lleno de amargura por las notas de su misión, experimenta sin embargo un gran ardor en fuerza de la presencia del Espíritu, que acompaña (Ez 3,14). Por eso a la desilusión inicial de Jeremías el Señor le insiste en la necesidad de una fe inquebrantable en su presencia, garantía de su misión y de su consuelo aun en la pura fe; por eso a la presencia de Dios en el hombre, éste ha de colaborar con una postura animosa y a ella se le exhorta al profeta $(\mathrm{Jr} 1,9)$, para poder gozar, incluso a nivel psíquico, del consuelo de Dios.

Una nueva fuente del consuelo vocacional está en la fidelidad del hombre a la llamada y a la misión. A Josué con la misma fuerza se le pide el ser valiente como luchador (Jos 1,6) que el serlo como cumplidor de la voluntad de Dios (Jos 1,7), que es lo que ha de dirigir toda su vida y darle su último sentido (Jos 1,8). Para Jesús de Nazaret son felices aquellos para quienes la pobreza y la persecución no ha sido una barrera en su seguimiento, en su aproximación al Reino (Mt 5,3.11s.; Lc 6.20-23) y en su respuesta activa a la Palabra de Dios (Lc 11,28), y el mismo Jesús vive en la expectativa ansiosa de su Hora (Jn 2,4; $7,8.30 ; 8,20 \mathrm{cp} 12,23 ; 13,1)$, de su Bautiśmo en sangre (Lc 12,50), donde recibe plenamente el amor y el consuelo de su Padre, porque pone su vida para recobrarla de nuevo (Jn 10,17s.), y esta misión del Padre ha sido para él alimento de su vida (Jn 12,50). Es, pues, en la escucha de la voz del Esposo (Jn 3,29), en la fidelidad a la Palabra de Jesús (Jn 13,17), en el amor y en la fe (Jn 20,29), donde se experimenta la verdadera alegría.

La esencia de este consuelo reside, pues, en la asistencia interior de Dios a su llamado, al que fortifica en sus palabras y en sus obras y le va dinamizando en toda su actividad ministerial ( 2 Ts 2,17), engendrando en él un modo de ser espiritual, efecto de la actuación del Espíritu, y que se concreta en «amor, alegría, paz, generosidad, benignidad, bondad, fidelidad, mansedumbre, autodominio» (Gl 5,22s), contra lo que ninguna ley externa vale, ya que es fruto de una experiencia interior y de un dinamismo vital. No es, pues, tanto efecto de una actuación humana, cuanto de la obra de Dios en el hombre, que así lleva 
una vida según Dios ( $\operatorname{Rm} 4,2)$. Por eso la Escritura canta la felicidad del hombre a quien Dios concede su santidad (Sl 1,1ss.), que no se logra por meros esfuerzos humanos, sino que es obra de Dios en cuanto causa la entrega del hombre, la fe, çon la presentación de Sí mismo en la Revelación (Gl 4,6.20). Este consuelo no reside tampoco en la realización de un ideal personal, ni en la aprobación del entorno, aunque éste se haya interiorizado, pues no depende tampoco de la propia conciencia (1 Cor 4,4), ya que, aunque ella no condene, la justificación y la verdadera santidad proviene sólo de Dios. Se trata de una participación en el Evangelio, por la que el hombre se va haciendo cada vez más evangélico (1 Cor 9,23 ), y por un avanzar en el amor cristiano la persona llega a gozar plenamente de la comprensión del Misterio de Dios, que es Cristo $(\mathrm{Cl} 2,2)$. Por eso la falta de éxito ministerial en la predicación del Evangelio es lo que puede tener en ocasiones sentido de desolación, aunque ésta puede ser causada también por Dios según sus planes (2 Cor 12,21).

Existen una serie de causas o situaciones concretas por las que puede llegar al hombre el consuelo de Dios en medio de su ministerio y en su vida consagrada. La Biblia presenta una amplia serie de ellas. En primer lugar, la Sda. Escritura, que ya desde el A.T. era un instrumento del consuelo de Dios y lo sigue siendo en cuanto abre a una esperanza continua y a la realización de una ilusión humana $(\mathrm{Rm} 15,4)$. Con ella, también la revelación de las gracias que Dios hace al hombre por su Espíritu y la comprensión de ellas dinamiza en la persona un gozo espiritual $(1$ Cor 2,12$)$. Y esto lo experimenta el hombre en su oración, en su contacto con Dios, que así es fuente de consuelo ( $\mathrm{Rm} \mathrm{4,6)} \mathrm{pe-}$ renne ( 1 Ts $5,16 \mathrm{~s}$.), como se expresa sobre todo en el gôzo de la adoración, en la confianza de la petición y en la alegría de la acción de gracias. Junto a ella, la fe personal, que se apoya en Dios y que da fuerzas $(\mathrm{Rm} \mathrm{4,20)}$ y valentía $(\mathrm{Rm}$ $9,23)$ y que se manifiesta también como fidelidad, fruto de la misma fidelidad de Dios en su llamada, que es lo que posibilita la respuesta fiel del hombre (Gl $6,16)$; por eso la permanencia en la fe es la que conduce a la experiencia del gozo verdadero $(2$ Cor 1,24$)$ y es así también como el testimonio de la propia conciencia en la fidelidad vivida es ocasión de consuelo auténticamente cristiano ( 2 Cor 1,12 cp 2,15.17; 4,2s.; 5,11; Gal 6,4). De este modo también el amor consuela, en cuanto en él se revela la vida de Dios Padre y de Jesús por la comunicación de su Espíritu (Jn 14,18-24), y fortifica para la santidad (1 Ts 3,11 ), como verdadero amor de Dios que es (1 Cor 2,9), y concede experiencia de su vida y de su gozo en cuanto participación del mismo amor de Cristo, que además conduce a consolar a los demás a través de la caridad (Fm 20). La esperanza es también causa de consuelo, con la perspectiva sobre todo de encon- 
trarse en el más allá con los seres queridos y especialmente con el mismo Cristo $(1$ Ts 4,18$)$.

Junto a esta vivencia de consagración, también la vivencia del apostolado dinamiza el consuelo en quien trabaja en el ministerio. Ya desde Moisés el éxito de su ilusión monoteísta a partir de la epifanía del Dios de los padres, que le seguirá asistiendo (Ex 3,12), es lo que constituye un elemento de consuelo, que lo vive también Jesús de Nazaret, al contemplar el derrocamiento del mal por medio de su obra $(\operatorname{Lc} 10,18)$ y la revelación de Dios en su ministerio a los pequeños (Lc 10,21s.). Después de él, el Paráclito, enviado por Jesús para hacerle presente y continuar su obra, será el causante principal del éxito apostólico (Jn 14,11-17 cp. He 1,8), donde manifestará la fuerza de Dios (1 Cor 1,24); 2 Cor 4,7 cp. 2,$9 ; 13,4)$ y el gozo espiritual, propio de la consagración (Rm 14,17). Esta experiencia de consagración y de santidad en la Iglesia es fuente de gozo para el apóstol (1 Ts 3,8 cp. 1 Cor 15,31), que se goza en la fe de la Iglesia (1 Ts 3,2.7), porque ve que la Iglesia es fiel a Dios $(\mathrm{Rm} 16,19)$ en virtud de su trabajo apostólico (Fp 1,25). De este modo también la amistad intraeclesial, que se realiza en la común fe y en el muto amor, y las noticias, que de esta vivencia de fe y de amor se reciben, causan el gozo apostólico (2 Cor 7,7) y además todo el progreso de la vivencia eclesial, aunque en ocasiones haya tenido que comportar una situación dura en el ministerio (2 Cor 7,9). Esta alegría está, pues, esencialmente determinada por la referencia de la Iglesia a Dios, bien supremo por el que el apóstol trabaja ( 2 Cor 7,13$)$, pero no prescinde de la alegría personal de que es este apóstol concreto el instrumento usado por Dios en su obra $(\mathrm{Cl} 2,5)$. Y entonces también la Iglesia se alegra de ver que hay personas concretas que se encuentran trabajando por su progreso espiritual (Cl 2,1s.).

Una causa especial y trascendente de este consuelo en la vida consagrada y ministerial es la escatología, la situación anhelada y beatificante de la unión definitiva entre Dios y el hombre, que se espera con una esperanza que no engaña, porque el amor de Dios se posee ya como prenda de esa realidad definitiva y futura $(\mathrm{Rm} 5,5)$. La seguridad de la esperanza es una fuente perenne de consuelo para el enviado de Dios, que se funda en la misma realidad cierta de Dios y de su triunfo (cf. Jn 16,33; 1 Pd 1,5 cp 2 Pd 3,9). Ya desde Moisés, que prefirió las contumelias del Mesías en virtud de su triunfo a los favores presentes en Egipto $(\mathrm{Hb} 11,26)$ y, pasando por todos los profetas, que se sentían animados por la esperanza (cf. Hb 11,39); 2 Pd 1,19), todo el A.T. refleja este consuelo de la esperanza, iniciado ya con Abraham en la promesa de bendición (cf. Gn 12,1-4 Hb 11,1s. 8s.).

La Iglesia cristiana se siente también consolada por la realidad perenne que supone Jesús para ella y que constituye una presencia del consuelo de Dios y al 
mismo tiempo una prenda y garantía de esa realidad beatificante de Dios, que cada vez se le hace más próxima. La Iglesia es consciente de que Jesús es Uno con Dios y que nadie puede arrebatarla a ella de las manos de su Señor (Jn $10,28 s s$. cp. Rm 8,38s.) y sabe además que Jesús ha orado por ella y ha pedido con su oración eficaz que los suyos estên siempre con él y puedan contemplar su gloria y participar de ella (Jn 17,24; $1 \mathrm{Jn} 3,2)$. Por otra parte, el mismo Jesús ha prometido el ciento por uno aquí, aunque sea con persecuciones, y después la vida eterna (Mt 19,28 Mc 10,29s Lc 22,28.30b) a quienes lo dejan todo por él y por el Evangelio (Mc 10,29 Lc 17,23); y él mismo en los momentos de su dolor se sintió confortado por la esperanza de lo que se le prometía ( $\mathrm{Hb}$ $12,2)$; por eso exhorta a su rebaño a no temer, aunque sea pequeño, pues el Padre se ha complacido en esta realidad y por ello quiere otorgarle su Reino (Lc 12,32 cp. Mt 11,25ss) y desea honrar así a todos los que siguen a Jesús y se encuentran donde él está, primero en tierra y luego en gloria (Jn 12,24ss, cp. 1 Cor 15,46$)$; por eso les exhorta también el Señor a sus apóstoles a gozarse de que sus nombres estén inscritos en el cielo y éste ha de ser su gozo fundamental más que el sensible de alegrarse de unos éxitos concretos en el ministerio (Lc $10,17-20)$, pues todo lo de este mundo pasa (1 Cor 7,31) y sus alegrías también (1 Jn 2,17s St 4,14;5,2s.), aunque sean espirituales (cf. Cl 2,20ss.).

La nota escatológica del consuelo está basada fundamentalmente en la misma nota escatológica de la llamada, que en definitiva es una llamada al Reino eterno de Dios; y el poder heredarlo es ya una fuente de gozo (1 Tm 6,12 ). Es así como Jesús consolaba también a sus apóstoles en el momento de su despedida visible, augurándoles un reencuentro más definitivo con él en la situación en la que él entraba y con la que así les preparaba un lugar para esa reunión definitiva (Jn 14,1ss.), exhortándoles a su vez a mantener con él la misma fe y confianza que tenían para con Dios y que sería fuente de gozo y un medio para ahuyentar todo temor (Jn 14,1.27). A partir de estas enseñanzas de Jesús, Pablo también consuela a los cristianos, proponiéndoles la situación final como fuente de energía en la vida con la esperanza de encontrarse para siempre con Jesús y con sus seres queridos (1 Tes 4,18$)$; y por ello han de trabajar fielmente en su cometido cristiano, sabiendo que su esfuerzo no es inútil en el Señor (1 Cor 15,58). Esto se aplica especialmente al trabajo apostólico (1 Cor 15,$10 ; 2$ Tm 1,$12 ; 2,1-13 ; 4,6 \mathrm{ss}$.) y a todo el esfuerzo ministerial y martirial, plasmado gráfica y dramáticamente en los últimos momentos del primer mártir, Esteban, que muere como Jesús, perdonando, y que se siente confortado con la contemplación del triunfo de Jesús a la derecha de Dios $(\mathrm{He} 7,56)$. Por eso a este consuelo, fundado en la esperanza cierta de la felicidad eterna, Pablo lo denomina un «consuelo eterno» $(2$ Ts 2,16$)$, que ha de dinamizar siempre las actuaciones vocacionales y que es mutuo, pues reside tanto en $f$ ! 
apóstol como en la Iglesia, y cuya manifestación definitiva se espera para el último día ( 2 Cor 1,14$)$, aunque ha. comenzado ya aquí y ahora, gracias a la participación humana en la misma gloria de Dios, en su mismo ser y en su quehacer $(\mathrm{Rm} 5,2)$. Es entonces, en el último día, cuando con la resurrección (cf. Jn 5,25-29 cp. 6,40-44) Jesús probará la obra del apóstol (1 Cor 3,5-13) y la aprobará definitivamente, causándole la alegría definitiva (1 Ts 2,19s. Fp $2,16 \mathrm{Ef} 6,8)$. Por eso esta contemplación del futuro dinamiza al apóstol (2 Cor $5,1 \mathrm{~s} .9)$, porque es la contemplación de un premio, que ciertamente le espera (1 Tm 6,14; $2 \operatorname{Tm} 4,8)$.

Este consuelo tiene un par de propiedades, que le caracterizan como elemento estructurante en la vocación y en la misión. La prifhera de todas es que se trata de un consuelo interpersonal, fundado en la relación personal, que media entre Dios y el hombre a partir de la misma constitución de la llamada vocacional. No es la institución o las obras de la persona lo que fundamentalmente le consuela, sino la persona de Dios.

Esta nota de interpersonalidad es la que aparece ya en todas las teofanías vocacionales del A.T. y en su aspecto confortante: es el Dios que llama quien asiste y fortifica para la misión. Por eso cuando Elías huye de la vida, huye hacia Dios, deseando morir; entonces se encuentra con unas ayudas, que le fortifican para llegar hasta el final de sus deseos, pero no para replegarse, sino para seguir en la misión (1 Ry 19,9-18). Es éste también el sentido del consuelo que Dios imparte con la llamada vocacional a Abraham (Gn 12,1ss.; 15,1-20; 22,15-18), a Moisés (Ex 3,16ss.; 33,5-9), a Baruc (Jr 45,1-5) y a Jonás, a quien consuela especialmente con su revelación y con el realismo que la verdad de Dios le aporta (Jon 4,1-11). Igualmente los apóstoles, como la Magdalena, a partir del consuelo que les imparte la resurrección de Jesús, han de verse fortificados para el testimonio (Jn 15,26s; 16,20;20,18).

En el Evangelio es la confianza en la persona de Jesús la que ha de ahuyentar el miedo y fortificar para el ministerio ( $\mathrm{Jn}$ 16,33); una confianza que equivale a la que se ha de poner en el mismo Dios (Jn 14,1ss). Esta presencia consoladora de Jesús, que da éxito a los trabajos apostólicos (Jn 21, 4-8), es la que aparece plasmada en las escenas evangélicas de la tempestad sosegada (Jn 6,16ss. pp.). También la persona del Paráclito, presencia continua de la asistencia de Jesús, tiene esta función de Consolador junto a los discípulos y apóstoles del Señor: es él quien hace presente a Jesús (Jn 14,16ss; 20,23 cp $1 \mathrm{Jn}$ 5,6 ) y quien habla en la paráclesis apostólica (Jn 15,26s. cp. 1 Tes 3,2 Rm 12,8 $\mathrm{Hb} 12,22 \mathrm{He} 13,15 \mathrm{cp}$. et Ap 2,7.11.17.26-29; 3,5s. 12s.21s.7, a la vez que asiste a los discípulos en toda las polémicas por el Evangelio (Mt 10,20 He 6,10). 
En esta vivencia espiritual del dinamismo de Jesús en los suyos es donde se experimenta realmente su consuelo en forma de amor (Jn 17,26; 15,9s cp 5,42; 10,$18 ; 14,21 \mathrm{ss}$.) y en forma de un aumento de conocimiento a partir de la revelación (Jn 16,23b) como un efecto de la escucha de la oración realizada en el Nombre de Jesús, que florece bajo el dinamismo personal y espiritual de Jesús en los suyos (Jn 15,16; 16,26). Esta relación interpersonal del consuelo es la que lleva al apóstol a gloriarse sólo en el Señor (Gl 6,14 Rm 5,11; 15,17 Fp 2,$16 ; 3,3$ cp. 1 Cor 1,$21 ; 3, \mathrm{~K} 21 ; 2$ Cor 10,17), pues este consuelo él lo ve como un don del Espíritu del Señor Resucitado (1 Cor 4,7) y como propio de Dios, que desde el A.T. aparece consolando no sólo a su Pueblo, como lo hace patente el Libro de la Consolación de Israel (Is 40-55), sino también a los individuos, como lo indican muchos de los Salmos, ya que sólo Yahweh puede fortificar auténticamente y sólo de él puede provenir el verdadero consuelo (Is 57,18 ), y sin él todos los otros consuelos son vanos (Is $28,29 \mathrm{cp} \mathrm{Zc} \mathrm{10,2} \mathrm{Jb}$ 21,34).

Pablo insiste también claramente en esta interpersonalidad del consuelo, manteniendo diferenciadas las funciones de las diversas personas divinas. Para él, es Dios Padre quien fortifica interiormente y quien concede el consuelo del corazón, como una respuesta a la postura oracional del hombre ( 2 Ts 2,17 ; $3,1.3)$, y por eso Pablo le denomina «el Padre del consuelo y de la misericordia», porque es él quien lo causa ( 2 Cor 1,3$)$. Dios Padre es el primer consolador $(2$ Cor $7 ; 4.6)$ y es quien presta su energía a todo según el don de su gracia y de su voluntad (Ef 1,11), concediendo las disposiciones de fuerza, amor, sobriedad y prudencia $(2 \mathrm{Tm} 1,7)$ y estando siempre junto al llamado, para fortificarle en su entrega y en su misión ( $2 \mathrm{Tm} 4,7)$. Un modo delicado del consuelo de Dios se realiza utilizando también según su providencia elementos que caen fuera del control ejercido por el hombre, como lo es para Pablo en un momento determinado de su vida la llegada de Tito (2 Cor 7,6). Pero es sobre todo en Cristo desde donde Dios Padre concede su consuelo, al posibilitar al hombre la experiencia de su dinamismo $(2 \mathrm{Tm} 2,1)$ por la presencia que el Señor ejerce en su Iglesia, comunicándola su vida y su fuerza (2 Cor 13,5); el recuerdo del Señor y la referencia a él producen en el apóstol el verdadero consuelo (Fp 4,10), quien reconoce además esta presencia consoladora del Señor en todos los detalles de amor, que va recibiendo en su ministerio apostólico (Fm 20). Para Pablo además, el consuelo de Cristo está fundamentalmente dinamizado por la unión con su Espíritu (cf. 1 Cor 6,17), que concede al hombre el mismo modo de ser de Cristo (Fp 2,1.5), su mentalidad (1 Cor 2,14ss), y con ella la experiencia del verdadero amor, alegría, paz etc., es decir, de todos sus dones $(\mathrm{Gl} 5,22)$ y concediéndole sobre todo de modo global toda la audacia necesaria para la vida cristiana, junto con la esperanza en la resurrección 
(cf. 1 Ts 1,10; 4,17b-18; 1 Cor 15,31s. 58; Rm 8,11.22-25 Fp 3,14; 2 Tm 2,11 ); y esto de modo continuo ( 2 Cor 5,6 ), posibilitando en el llamado el fervor de la vocación $(\mathrm{Rm} 12,11)$ en la referencia a Dios $(\mathrm{Rm} 15,13)$ y haciéndole partícipe de la fuerza de Cristo ( $R m 15,17 \mathrm{~s}$.), ya que él es la fuente de la santidad y juntamente el dinamizador del gozo y de la paz, que acompañan siempre a la verdadera santidad ( $\mathrm{Rm} 14,17)$.

La referencia a Dios, propia de la vida consagrada, y la sabiduría, que en ella se adquiere, es un matiz especial del consuelo, que brota en esta relación interpersonal entre Dios y el hombre, y del efecto, que la acción de Dios produce en el hombre (1 Cor 1,30), es decir, de una acción, que, partiendo de Dios, mueve al hombre a consagrarse a él desde lo más íntimo de su personalidad humana, desde su propia conciencia, desde el centro de su identidad, donde experimenta el consuelo de Dios, al sentirse integrado en lo más íntimo de su ser desde el mismo Dios (2 Cor 1,12). Y como todo esto es un don, que desde Dios conduce a Dios, el consuelo del Señor hace florecer en el hombre el cántico del agradecimiento, con el que se expresa la fuerza del consuelo de Dios en el hombre. Es así como brotan los cantos de agradecimiento en el A.T., especialmente en figuras vocacionales como Jacob (Gn 49,1-28), Moisés (Ex 15,1-21 Nm 21,17s. Dt 32,1-44; 33,1-29), Débora (Jc 5,1-31), Ana (1 Sm 2,1-10), David (2 Sm 22,1-23,7), Salomón (1 Ry 8,22-40p), Isaías (Is 12,1-6), Judít (Jdt 16,1-17), Daniel (Dn 2,20-23; cp. 3,24-90), Habakuk (Hab 3,1-18), Tobías (Tb 12,21-14,1); y también en el N.T. con María (Lc 1,46-57), Zacarías (Lc 1,67-79) y Simeón (Lc 2,29-32). Jesús por su parte salta de gozo ante la acción de Dios en su misión (Lc 10,21ss.) y se alegra de verse escuchado siempre por su padre Dios (Jn 11,41s.). Pablo también da gracias, no sólo porque él se ha sentido liberado de un peligro (cf.v. gr. He 27,35), sino gozándose de que el canto de agradecimiento se realice en la presencia de Dios, al estar producido por la fe, que proviene de él (1 Ts 3,9), y por eso reconoce que este agradecimiento gozoso es a su vez un nuevo aliciente en el trabajo apostólico y así siempre el aumento del agradecimiento para gloria de Dios hace que el apóstol no desfallezca (2 Cor 4,16s.).

La segunda característica del consuelo de Dios en el llamado es que este mismo consuelo dinamiza la acción de consolar, propia de la misión apostólica. Esto había ya acontecido en los antiguos profetas. Son ellos los primeros consolados por Dios y ellos a su vez transmiten el consuelo divino a su Pueblo. El Siervo de Yahweh cada mañana se pone a la escucha de la Palabra del Señor, para poder decir al cansado una palabra de consuelo (Is 50,4); y por eso los oráculos de la consolación se entienden como un resultado de la oración (cf V. gr. Is 26,7-27,13). El haber sentido una llamada de Dios para la salvación es lo que le hace al Déutero-Isaías invita a la alegría con sus cantos; y a partir de es- 
ta dinámica la misma Sión se siente también mensajera del consuelo (Is 40,9; $52,8)$, que ha de invadir no sólo a quienes se encuentran cerca de Jerusalén (Is $41,16 ; 51,11 ; 52,9 ; 54,1 ; 55,1)$, sino además a todos los convocados (Is 42,11 ) hasta el confín de la tierra (Is 42,10 ) e incluso a todo el universo, que ha de participar de esta alegría religiosa (Is 42,10s; 43,20;44,23; 49,13; 55,12); de este modo todo el mensaje profético está transido de alegría, como mensaje que se basa en la certeza de la salvación; así lo indica la forma verbal hebrea del perfecto, usada en estos oráculos. El consuelo de Dios, que se transmite por su palabra y su Ley (cf. Sl 119,1s.16.24.32.50.54), por la Escritura (1 Mc 12,9; 2 Mc 15,9 cp Rm 15,4), por sus mensajeros, como los ángeles (Lc 2,10; 22,43 cp Jn 12,29), Daniel (Dn 13,60) o Habakuk (Dn 14,33-39), se transmite sobre todo por el conjunto de los profetas, quines no tanto amenazan cuanto consuelan y, para poder transmitir el consuelo de Dios, es también para lo que llaman a la conversión con sus invectivas; por eso su recuerdo ha quedado fundamentalmente vinculado a su ministerio de consolación (Si 48,24; 49,10). Este consuelo es el que en el umbral del N.T. esperaba Simeón y con él consuela también a todos los que le rodean ( $\mathrm{Lc} 2,25)$. Jesús por su parte no sólo actualiza la función consoladora del Mensajero de Yahweh (Is 61,2, cf. Lc 4,1722), sino que es la misma presencia personal del Consuelo de Dios para su Pueblo (Lc 2,25.58) y así lo ofrece con la remisión de los pecados (Mt 9,2 cp. $2,21 ; 26,28)$, a la vez que lo proclama perfecto para quienes entran en su radical seguimiento (Mt 5,1ss. cp. Lc 6,20ss), pues él proporciona el verdadero descanso a los fatigados (Mt 11,28) e invita a sus mismos discípulos al descanso (Mt 6,31), mientras a Pedro le anima a no desfallecer nunca por falta de confianza (Mt 14,31).

Los pastores de la Iglesia continúan esta función consoladora en medio de ella (He 15,31) como parte de su ministerio profético (1 Ts 2,11s.; 1 Cor 14,3). El fin de esta actividad tiende a poder transmitir a todos el consuelo, con el que el mismo apóstol se siente consolado por Dios $(2$ Cor 1,4$)$, y es para esto para lo que el Señor le consuela a él en medio de todos sus trabajos y padecimientos apostólicos (1 Cor 1,6). El trabajo apostólico tiende, pues, a producir en la Iglesia un consuelo, que es presencia de amor a partir de la comprensión del Misterio de Dios en Cristo ( $\mathrm{Cl} 2,2 \mathrm{~s})$; con este ministerio apostólico de caridad evangélica, que transmite el mensaje de Dios, la Iglesia se siente divinamente consolada, como el mismo apóstol, y participa así de su consuelo y, a través de él, del consuelo de Dios. Porque es la predicación la que anuncia el consuelo de los Bienes mesiánicos (Rm 10,15); y la instrucción y la exhortación, con las que se goza la Iglesia, son el fruto de la actividad profética en medio de ella (1 Cor $14,29 \mathrm{~s}$ ); es así como la profecía consuela a la Iglesia (1 Cor 14,1.3ss.12). Por eso las palabras de la predicación son las que dan la 
salud plena $(2 \mathrm{Tm} 1,13)$, que está producida por la enseñanza verdadera ( $2 \mathrm{Tm} 4,3)$; y por eso también la Iglesia se alegra tanto del trabajo apostólico $(\mathrm{Cl} 2,1 \mathrm{~s}$.). La presencia del apóstol en ella le es además causa de inmensa alegría, en cuanto que le coloca en referencia total a Cristo (Fp 1,26).

Esto es lo que constituye la paráclisis o consolación apostólica, con la que Dios se encuentra exhortando en el mismo apóstol (2 Ts 5,10 cp. 1 Ts 2,3; 2 Cor 6,1$)$ y que se realiza con la Buena Noticia de la Salvación, comenzando ya con Juan el Bautista (Lc 3,10-14.18 He 2,20), pues ella aporta el consuelo del Espíritu Santo (He 9,31), que es lo que imparte el apóstol con su predicación (He 13,13 cp. Hb 13,22; 1 Pd 5,12 Jds 3). Esta función apostólica se ejercita «en Cristo» (Fp 2,1; 1 Ts 4,1), «en su Nombre» (1 Cor 1,10), «en el amor del Espíritu» (Rm 15,30 cp. 2 Cor 10,1), «en la misericordia de Dios» (Rm $12,1) \mathrm{y}$, por lo tanto, es distinta de cualquier exhortación meramente ética. Pablo anima también a sus colaboradores a seguir ejerciendo esta función (1 Tm 5,11; 6,2 Tt 2,6.15; 2 Tm 4,2 cp. Heb 3,13; 10,25); y ellos lo hacen ( 1 Ts 3,2 cp. He 11,$23 ; 14,22 ; 16,40 ; 20,25$ ), como el mismo Pablo lo ha realizado, al modo de una madre que consuela a sus hijos (1 Ts 2,12). En todo esto

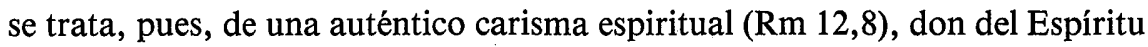

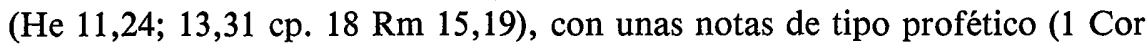
14,3.31), y esta situación de consolación expresa además toda la integración del consagrado y su sentido en la vida.

Son varias las manifestaciones, en las que esta integración personal se expresa; ellas afloran en las diversas esferas que configuran todas las zonas de la personalidad. Así, por ejemplo, en la zona concupiscible aparecen la alegría y el gozo, la paz y la confianza; en la zona irascible se desarrolla la fuerza, sobre todo para momentos de dificultad, y emerge también la vivencia de libertad; por fin, la zona pasible experimenta su integración como gloria y salvación.

La alegría y el gozo son la señal externa de que la vida ha triunfado en la persona, pues el verdadero dinamismo de la vida plena de Dios en el hombre se da siempre con una profunda alegría $(\mathrm{Cl} 1,11)$. En el A.T. existen ya muchas referencias a la alegría, como experiencia concomitante a la posesión de diversos bienes, pero para la teología bíblica toda alegría, que no esté basada en Dios, es efímera, pues la verdadera alegría depende sólo de Dios $(\mathrm{Jr} 7,34)$, fuente de la vida; y por eso él priva de sus dones - y consiguientemente de la alegría que los acompaña - a quienes no le han servido con fidelidad, como símbolo de la pérdida de la cercanía de Dios (Dt 28,22-24). La alegría continua en Yahweh es ya proverbial en el A.T. y se manifiesta en las fiestas y en el culto (Dt $12,7.18,30 \mathrm{~s} \mathrm{S1} \mathrm{81,2s.} \mathrm{Esd} \mathrm{6,22} \mathrm{Neh} \mathrm{12,27} \mathrm{etc.)} \mathrm{y} \mathrm{en} \mathrm{la} \mathrm{misma} \mathrm{creación}$ 
(Gn 25,8 Sl 37,11; 113,9 etc.); su fundamento estriba en la elección del Pueblo (S1 149,2ss; 95,5-11), en la historia salvífica y sus gestas divinas (SI 74,13-38), en la fidelidad de Dios a su alianza (Sl 31,8s.; 145,7s.) y en los bienes mesiánicos (Is 49,1ss.), concretados en ocasiones en figuras típicas como la del rey venidero (Zc 9,9); pero siempre esta alegría tiene un objeto personal, que es el mismo Dios (Is 44,23) y sus atributos, en definitiva su amor fiel (Is 44, 23). Por su parte, Dios concede esta su alegría, al otorgar sus bienes y, sobre todo, el más excelente de todos, la Sabiduría ( $\mathrm{Sl} \mathrm{9,16} \mathrm{Si} \mathrm{4,12),} \mathrm{el} \mathrm{conocimiento}$ de su voluntad y la ley (Sl 1,3; 19,9; 119,162), su Palabra $(\operatorname{Jr} 15,16)$, que hace que el hombre de Dios se goce sólo en él con una alegría fortificante (Neh 8,10 Est 14,18), aunque falten todos los otros bienes (Hab 3,16-19).

La existencia de Jesús de Nazaret está también transida de esta nota de alegría, comenzando ya desde el mismo nacimiento de su Precursor (Lc 1,14) y prolongada en el cántico de su madre ( $\operatorname{Lc} 1,47$ ) y en el anuncio de su nacimiento (Lc 2,10 ), que se manifestará luego definitivamente en la escucha de su voz (Jn 3,29) y de su palabra (Jn $15,11 \mathrm{cp} .16,20-23)$, ya que el mismo Jesús ha sido ungido con óleo de alegría hasta el final de su carrera, incluso hasta la Cruz (Heb 1,9 cp. 12,2), y por eso todo su ministerio expresa la alegría que siente en su realización, al revelarse Dios a los pequeños (Lc 10,21) y al operar la remisión de los pecados (Lc 15,5.7.10). Él quiere que esta alegría la sientan quienes comparten sus mismos valores (Lc 15,32) y promete la alegría a los suyos, aunque se encuentren en persecución (Mt 5,12pp), sobre todo a partir del encuentro posresurreccional con él (Jn 16,20.22) y ante la visión del resultado apostólico (Jn 4,36). Para él, toda la presentación de su Reino, de la realeza de Dios en el hombre, está llena de alegría, como lo muestran sus parábolas nupciales (Mt 22,2ss cap. Jn 2,1ss. cf. et Lc 14,12ss.) y sus alusiones al tesoro del Reino (Mt 6,20; 12,35; 13,52; 19,21) y a la perla (Mc 13,44ss.). Por eso la alegría de Jesús se prolonga en su Iglesia (Lc 24,52 Ap 19,7) y es la vivencia del dinamismo de Jesús en el hombre donde se experimenta esta alegría auténticamente cristiana (Jn 3,29; 4,36;13,17;15,11;16,20-24; 17,13;20,29).

La causa radical de este gozo, según la doctrina apostólica, es la santidad de Dios en el hombre, que le integra y le llena de alegría y de paz (Rm 14,17); por eso este gozo va progresando a medida que progresa la fe y la entrega (2 Cor 1,24$)$. Y con la fe, también la esperanza y lo que ella engendra en el llamado $(\operatorname{Rm} 12,12)$ es causa de esta alegría sólo en el Señor $(1$ Cor 15,30$)$, que es el fin de toda la esperanza cristiana (cp. Jn 14,1ss. 17s; 16,33; 1 Ts 4,17b-18).Pero sobre todo el amor es causa de alegría en el hombre, en la medida en que él ama la revelación de Dios y se goza en ella (1 Cor 13,6), a la vez que se goza además en todos los bienes que le llegan del Señor $(1 \mathrm{Tm} 6,17)$ a través de la caridad de la Iglesia (Fp 2,29). Todo lo demás, que expresa la referencia del 
hombre a Dios, como la petición y la acción de gracias, es también fuente de alegría espiritual ( 1 Ts $5,16 s s$.).

Pero lo que dinamiza de modo más peculiar la alegría en el apóstol es el éxito en su ministerio ( 1 Ts $2,19 \mathrm{~s}$.). Ya Juan manifiesta que no tiene alegría mayor que la de saber que sus hijos caminan en la luz ( $2 \mathrm{Jn} 4 ; 3 \mathrm{Jn} 3 \mathrm{~s}$.). En Pablo esta alegría se hace desbordante: él posee una alegría carismática, ante Dios (1 Ts 3,9), al ver que los suyos permanecen fieles en el Señor (1 Ts 3,8); y esta fidelidad, causa de su alegría, la constata Pablo en varios momentos: al recordar la unión del apóstol con la Iglesia (Fp 1,4) y la común fe $(2 \mathrm{Tm} 4,1)$, ante la acogida que la Iglesia hace del legado apostólico $(2$ Cor 7,13$)$ y al percibir la caridad práctica de los miembros de la Iglesia (Fm 7); y Pablo se goza sobre todo con el anuncio de Cristo, de cualquier modo que se realice (Fp 1,8). Pero en toda esta alegría actual no deja de resonar tampoço la nota escatológica y final de toda alegría verdaderamente cristiana: Pablo se goza al vivir esperando la manifestación definitiva de Dios, incoada ya en Cristo (Tt 2,13), pues para el Día de Jesús espera él la aprobación culminante de su trabajo apostólico $(2$ Ts $2,19 \mathrm{~s}$.).

Es especialmente en la tribulación donde esta alegría apostólica y ministerial tiene un significado especial y donde resalta su aspecto típicamente cristiano y vocacional. Si la prueba tiene un aspecto de tristeza, su fin sin embargo es un gozo, pues tiende a una perfección (Heb 12,11). Por eso los primeros apóstoles se gozaban ya de poder sufrir en el nombre de Jesús $(H e-41)$ y así también las iglesias primitivas sufrían con gozo el despojo de sus bienes y las privaciones (Heb 10,34), tanto Macedonia $(2$ Cor 8,10$)$ como sobre todo Tesalónica, a la que el Espíritu Santo concede su gozo, porque ha recibido el Evangelio a pesar de las tribulaciones que ello comportaba (1 Ts 1,6). Si el cristiano ha de alegrarse en su padecer ( $1 \mathrm{Pd} 1,6 ; 4,13 \mathrm{St} 1,2)$, al imitar a Cristo en su seguimiento (Mt 5,2-12), mucha más el apóstol. Por eso Pablo manifiesta una perpetua alegría en medio de sus tribulaciones apostólicas $(2$ Cor 7,4$)$ y, aunque en ocasiones tiene motivos de cierta tristeza, se encuentra siempre íntimamente alegre $(2$ Cor 6,10$)$, porque Cristo es la fuente de su vida $(G 12,20)$. Esta asistencia interior del Señor, ya presente también en el A.T. (Ex 3,12 Jos 1,9.17 Jc 6,16 Jr 1,8), es la que desde Cristo da vigor a los apóstoles del N.T. (Mt 28,20b He 18,9) y así los padecimientos apostólicos completan lo que falta a la pasión de Cristo en favor de su Cuerpo, la Iglesia $(\mathrm{Cl} 1,24)$, y en esta debilidad apostólica se va operando la vida y la fortaleza de la Iglesia ( 2 Cor 13,9), al mismo tiempo que en su debilidad el apóstol sólo puede poner su gozo en el Señor (1 Cor 15,30s.). Por eso esta alegría en el padecer sólo puede ser carismática y es así como está causada sólo después de la venida del Espíritu en Pentecostés (Fp 1,19 cp. He 13,52) y sólo a partir de la fe y de la referencia 
a Dios (Rm 15,13). Por esta razón es una alegría que se posee ante Dios (1 Ts $3,9)$ y hay que buscarla sólo en él $(1$ Cor 1,13$)$ y en su revelación $(1$ Cor 13,6$)$, pues no es subjetiva, ni simbiótica ( 2 Cor 10,17 ), ya que es la referencia al Señor la que la causa (Fp 3,1.3) a partir de una esperanza sólo en él (1 Cor 15,30).

A esta alegría exhortaba Pablo (1 Ts 5,16ss.), de forma que la Iglesia se alegre en el trabajo y en la oblación del apóstol (Fp 2,18) y también en su presencia, por la referencia que él determina hacia Cristo (Fp 1,26) y por la posibilidad de lograr sus frutos, que son en definitiva el progreso en el gozo auténticamente cristiano $(2$ Cor 1,24$)$. Es en la referencia al Señor donde se produce para Pablo el gozo permanente (Fp 3,1) y por eso él pide oraciones para seguir ejercitando con alegría su ministerio ( $\mathrm{Rm} 15,30)$, ya que la alegría le da fuerzas a Pablo y le sirve de experiencia de salvación; y es a partir de la oración de los suyos como él siente que le llega el consuelo del Espíritu (Fp 1,19). En correspondencia, Pablo se sentirá también lleno de alegría, al realizar su oración por la Iglesia (Fp 1,4).

Junto con el gozo, la presencia del Señor en el hombre y su consolación aporta la paz como experiencia de integración personal. El cristiano está llamado a la paz $(1 \mathrm{Cor} 7,5)$ y destinado a vivir la paz $(\mathrm{Cl} 3,15)$. Por eso la pacificación interior es quizás la nota primaria en la integración vocacional de la persona, incluso cuando la alegría se serena. Por eso es también el primer deseo de Pablo en sus saludos, como efecto de la gracia de Dios en el hombre ( 1 Ts 1,$1 ; 2$ Ts 1,2 Gl 1,3s. 1 Cor 1,$3 ; 2$ Cor 1,2 Rm 1,7 Fp 1,2 cf. et. Ap 1,4). La paz se encuentra al comienzo y al fin de todo el proceso por el que Dios consuela al llamado y es la señal de su verdadera presencia en él, pues ha de mantenerse aun en medio de cualquier tribulación. Si al principio del proceso vocacional, Dios asiste con frecuencia por medio de una alegría carismática, que ayuda a superar todas las dificultades y que confirma al llamado en su propósito, la situación permanente de una persona integrada es la de la paz, donde se muestra su acceso a Dios $(\mathrm{Rm} 5,1 \mathrm{Cl} 1,20 \mathrm{Ef} 2,15)$ y su relación permanente y personal a Cristo, que es la misma Paz (Ef 2,14). Para la concepción bíblica, la paz en su aspecto humano indica armonía, perfección de todo el ser y de todas sus relaciones; por eso esta paz fue parte fundamental del anuncio profético, como resumen de todos los bienes de la salvación (Is 2,2ss; 7,14; 11,1-5; 53,5 Mq 5,1ss Zc 9,9s), y tiene su base y fundamento en Dios y en el cumplimiento de su voluntad ( $\mathrm{Lv} 26,6.12 \mathrm{Dt} 8,14$ Is $11,3 \mathrm{ss} ; 32,15-18 \mathrm{SI}$ $85,9-14 ; 119,115)$ a diferencia de las falaces promesas de paz, anunciadas frecuentemente por los falsos profetas (cf. 1 Ry 22,5-18 Jr 6,14; 14,13; $28 \mathrm{Ez}$ $13,16)$. Por esto también se ve a la paz como obra del mesías de Dios, a quien se denomina el Príncipe de la Paz (Is 9,5). 
Para el N.T., la obra de la paz acompaña toda la actuación de Jesús: se manifiesta en su aparición en la tierra (Lc 1,79; 2,14; 4,17ss Mc 5,34) y se transmite en su Misterio Pascual (Lc 19,38.42; 24,36 Jn 20,19s); en su misma vida refleja Jesús esta integración, cuando por su fidelidad a Dios aparece incluso en paz con las alimañas del desierto (cf. Mc 1,13 cp. Os 2,20 Is $11,16 s s ; 35,9 \mathrm{Ez} 34,25$ ) y en señal de su triunfo sobre el mal él calma las tempestades (Mt 8,27pp) y sostiene en medio de ellas a su Iglesia (Mt 14,29ss.); a sus discípulos les manda saludar con su paz y entregarla a quienes son dignos de ella (Mt 10,13 Lc 10,5ss.), una paz, que no es tranquilidad, sino proceso de integración (Mt 10,34 cp. 13 cf. et. Lc 2,$29 ; 7,50 ; 8,48$ ) y por eso es distinta de la paz del mundo (Jn 14,27); es la paz, que Jesús opera en las personas con la remisión de los pecados a partir de su Misterio Pascual y es la paz que él manda transmitir con la misión en su Iglesia y con la fuerza y la presencia de su Espíritu Santo, plenitud del ser de Dios en el llamado (Jn 20,19.21.26).

Pablo desarrolla en sus cartas una teología de la paz, cuyo origen lo radica en la llamada de Dios, que se ordena a la paz y que la produce $(1 \mathrm{Cor} 7,15)$, como ya el mismo Isaías había intuido que era la elección de Dios lo que daba el verdadero derecho a la paz (Is 43,3s; 48,15). La condición necesaria para que se produzca esta situación interior de integridad y de paz es la respuesta a la vocación de Dios, es decir, el realizar el bien contemplado (Fp 4,9). Por eso Pablo coloca la causa de la paz en la santidad de Dios en el hombre, a quien junto con su gozo esencial transmite su paz también ( $\mathrm{Rm} \mathrm{14,17).} \mathrm{Esta} \mathrm{santi-}$ dad, causa de la paz, viene especificada con diversos términos en la literatura paulina: la adhesión al cristianismo (Gl 6,16), la justicia de la fe $(\operatorname{Rm} 5,1)$, la consagración del hombre a Dios (1 Ts 5,23), la fe y la concomitante referencia al Señor ( $R m$ 15,13), el caminar según el Espíritu (Rm 8,5ss.); es decir, en el fondo la paz cristiana es siempre la experiencia que brota de un amor, que nace de la fe (Ef 6,24s.). Y como su causa inicial se encuentra en el Dios que llama, por eso se le denomina también a él «el Dios de la Paz» (1 Cor 14,33), en cuanto que él la concede (1 Ts 5,23) como fruto de su amor fiel al hombre (Gl 6,16). Pero Dios Padre concede esta paz en el proceso de ir sometiendo todas las fuerzas contrarias al cristiano (Rm 16,19ss.); y esta paz, fruto de la victo-

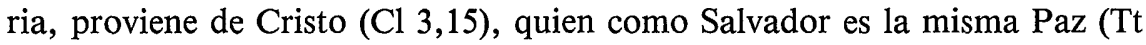
1,4) y la realiza en su obra $(\mathrm{Cl} 1,19$ Ef 2,14s.). Para completar la nota trinitaria, Pablo menciona también al Espíritu como autor de la paz ( $\operatorname{Rm~15,13),~}$ que, al ser don de Dios, es también fruto concedido a la oración y por eso hay que pedirla (1 Ts 5,23 Fp 1,2), sobre todo en oración de deseo para la Iglesia ( 1 Ts 1,$1 ; 2$ Ts 1,2 etc.), como efecto de la gracia de Dios y de Cristo en ella (Gl 1,3s; 1 Cor 1,3; 2 Cor 1,2 Rm 1,7).

Como propia de un proceso de integración, esta paz depende de la libera- 
ción del pecado y de las estructuras del mal ( $\mathrm{Gl} 1,3 \mathrm{~s}$.), pero al mismo tiempo supone una referencia de consagración a Dios en todo el conjunto del ser humano -espíritu, alma y cuerpo (1 Ts 5,23 cp. Héb 13,20)-, que, al quedar integrado desde sú relación a Dios, refleja también la capacidad de acceso a Dios en Cristo ( $\mathrm{Rm} 5,1)$, que es la $\mathrm{Paz}(\mathrm{Cl} 1,19 \mathrm{Ef} 2,14 \mathrm{~s}$.) y quien concede la paz como gozo en la vida, como sensación alegre de vivir una vida plenamente integrada en todas sus relaciones ( $\mathrm{Rm} 8,5 \mathrm{ss}$; 14,$17 ; 15,13)$. Y entonces la consecuencia en el hombre de esta paz es el ser pacífico ( 2 Cor 13,11 ), pero de forma dinámica, pues la paz de Dios le ha disuelto las preocupaciones nocivas, como primer fruto de su consuelo y de su respuesta a la apertura del hombre (Fp 4,7 Ef 6,23), le guarda además todos los sentidos y planes del corazón como un centinela en su referencia a Cristo de modo continuo $(\mathrm{Fl} 4,7)$ y, al presidir la paz del corazón humano, le hace también planear todo lo referente a la pacificación y al aumento de la comunión eclesial, favoreciendo así la unidad (Ef 4,5), es decir, la hace obrador de paz y en ello le concede la felicidad (cf Mt 5,9). Por eso Pablo concibe todo su apostolado ordenado a un llegar a gustar el reposo juntamente con la Iglesia $(\mathrm{Rm} 15,33)$ y por ello, imitando a Cristo quien, al hacer la reconciliación la anuncia (Ef 2,17), también Pablo se presenta con la invitación de Dios a la reconciliación en Cristo ( 2 Cor 5,20), para llegar así a la verdadera paz (cf. et. $1 \mathrm{Pd} 3,11$ ).

Una vez que la persona se encuentra interiormente integrada en la paz, $d t$ esta situación brota la confianza, también como experiencia del ccrsuelo de Dios en el hombre y como prenda de su presencia. El Siervo de Yahweh deposita su juicio y su causa en Dios, a pesar del poco éxito que experimenta en su ministerio (Is 49,4), como lo hace el mismo Jesús en el momento de su muerte $($ Lc 23,46$)$. Y a esta confianza inquebrantable en la providencia de Dios invita Jesús (cf. Mt 6,25-34) como resultado de la cercanía a él a partir de la remisión de los pecados (Mt 9,2), como fruto de la salvación por la fe (Mt 9,22) y como efecto de la victoria sobre las fuerzas del mal (Mc 6,50 Mt 14,27) a partir sobre todo de su Misterio Pascual (Jn 16,23 cp. 14,1ss.).

Pablo exhorta a mantenerla incluso en medio de las dificultades ( $\mathrm{He}$ 23,11 ) y él mismo la experimenta como suficiencia y capacidad apostólica, que le viene de Dios y que se ordena a configurarle como ministro de la Nueva Alianza ( 2 Cor 3,5$)$; por eso se muestra seguro en su ministerio ( 2 Cor 7,16 ; $10,1 \mathrm{~s}$.) y afirma que quienes sirven bien en la obra de la fe logran gran confianza por la esperanza que Cristo deposita eh ellos $(1 \mathrm{Tm} 3,13)$, ya que la fe y la entrega en la vocación concede al llamado el apoyarse en Aquel de quien se ha fiado $(2 \mathrm{Tm} 1,2)$, haciendo de esta confianza una experiencia típicamente cristiana $(2$ Cor $5,6.8)$ por su referencia personal a Cristo, apoyo de quien se entrega a él aun en medio de cualquier dificultad (Heb 13,6). 
Es así como brota también en la persona vocacionalmente integrada la fortaleza como experiencia de la asistencia de Dios en la misión de aquel a quien él ha llamado. Esta fortaleza se observa ya en el ministerio de los profetas de Israel (Mq 3,8); Dios le hace fuerte al profeta como contrapartida a la dureza del pueblo, pues la bondad no se ha de doblegar ante la maldad (Ez 3,8ss.); Amós continúa intrépido en su ministerio a pesar de los obstáculos de la política, porque se siente carismáticamente respaldado por Dios (Am $7,14 \mathrm{~s}$.); el Siervo aparece como una espada afilada y una flecha aptísima, pero en la aljaba de Yahweh (Is 49,2), que constituye su fuerza para la misión (Is 49,5), y por eso no se retrae en su ministerio (Is 50,4-10); para èl mesías se presagia la misma experiencia de la fortaleza de Dios en su vida (Is 9,5; 11,2). Y en el N.T. los apóstoles muestran esta misma valentía $(\mathrm{He} 4,1-22)$ y sobre todo Pablo (He 9,27), quien adscribe a la conciencia de la vocación la fuerza para la misión (cf. 2 Cor 5,13). Esta valentía la había mostrado ya Juan el Bautista ante Herodes (Mt 14,4) y también Jesús (Lc 14,31ss.), que se mostró poderoso en obras y en palabras $(\operatorname{Lc} 24,19)$ y que predijo la presencia de su fuerza para la época de la Iglesia (Mt 24,30); 26,64 Mc 14,62 Lc 22,69) a partir de su Resurrección (He 4,23 cp. Rm 1,4), de forma que sus discípulos no actuarán ya por sus propias fuerzas $(\mathrm{He} 3,12)$, sino en virtud del dinamismo de Dios en ellos (He 1,7s), que les capacitaría para dar con valentía testimonio del Evangelio (He 26,22) a partir del dinamismo que la Palabra de Jesús suscitara en ellos (Jn 16,1.4.6.33).

Concretamente Pablo siente en su vida esta fuerza de Dios $(\mathrm{Ef} 1,19)$ y no se acobarda de anunciar todo el Misterio de Dios (He 20,7). La fuerza, que él experimenta, la adscribe al Dios presente en su vida $(2 \mathrm{Tm} 4,17)$ desde lo más íntimo de su ser (1 Ts $2,2 \mathrm{Gl} \mathrm{3,5;1}$ Cor $12,4 \mathrm{ss} ; 2$ Cor 4,8 Cl 1,11 Ef 1,18s; 2 Tm 1,8) por la acción del Espíritu (Gl 3,5; 1 Cor 2,4. 10; 12,4ss. 7 Tt 3,8), que revela con fuerza a Cristo (Ef 3,5) como norma dinamizante de todo el actuar $(\operatorname{Ef} 2,12 ; 3,16)$. Por eso esta fuerza se adscribe también a Cristo y a su acción (1 Cor 1,8 Ef 3,16 ), ya que él vive como Resucitado con la fuerza de Dios y esta misma fuerza es la que él transmite a la Iglesia (1 Cor 13,3s.), concediéndola energías para el ministerio apostólico $(\mathrm{Cl} \mathrm{1,29)}$.

Es a este ministerio, pues; al que primordialmente se ordena toda la experiencia carismática de la fuerza de Dios, que, aunque en último término tiende a potenciar la energía para la santidad $(1$ Ts 3,11$)$, sin embargo se explicita de forma más clara en las manifestaciones de esta santidad para la vida concreta de consagración. Por eso el objeto y el fin, para el que se concede esta energía, es para encontrarse con Cristo $(\mathrm{Gl} 5,6)$, pero esto de un modo práctico $(\mathrm{Cl}$

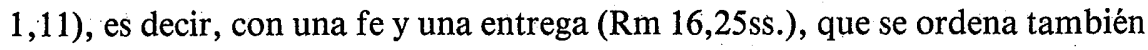
al Cristo eclesial en orden a la construcçión de su Cuerpo (Ef 2,12) por el mi- 
nisterio de la palabra ( 1 Ts 2,$12 ; 2$ Cor $4,13 \mathrm{ss}$.), que tiende siempre a producir la fe y la entrega cristiana (1 Cor 2,4$)$. La experiencia de esta fuerza está ordenada, pues, al servicio del Señor y a la utilidad común de la Iglesia (1 Cor 12,4 ss. 7 ), que se concreta en el servicio evangélico (Ef $3,17 \mathrm{~s}$.), que hace avanzar el kerygma ( $2 \mathrm{Tm} 4,7)$ por la predicación del Evangelio $(2 \mathrm{Tm} 1,8)$, trabajando en lo que se puede denominar la lucha apostólica $(\mathrm{Cl} 1,29)$. Es para este apoyo y consuelo, que proviene de la mutua fe, para lo que Pablo quiere ver a los suyos y comunicarles este carisma de fortaleza en su vida cristiana ( $\mathrm{Rm}$ 1,10ss.).

Pablo experimenta esta fuerza no sólo en el poder que siente para superar todas las dificultades (1 Cor 10,13), sino en la capacidad que nota para decidir en la Iglesia con el Espíritu de Jesús ( 1 Cor 5,3ss. cp. 2,4; 7,40), de forma que nunca deja de actuar ni de ejercer su autoridad (He 15,24). Es una fuerza, que no proviene, como dice él, de error, mentira o impureza, sino de la conciencia de haber sido elegido por Dios para el ministerio apostólico (1 Ts 2,3); brota de la escucha de la fe (Gl 3,5 Rm 1,16 Ef 1,18s.), que mueve por el amor (Gl $5,6)$, al haber interiorizado a Cristo (Ef 3,16$)$ como palabra (1 Cor 1,18$)$ y como modelo (1 Cor 1,23s); y desde la unión con él como Crucificado y Resucitado (Fp 4,13) nace este amor, que fortifica para la santidad (1 Ts 3,11), y esta esperanza, que mueve a todas las empresas a partir de la fe en el Señor Muerto y Resucitado ( 2 Cor $4,13 \mathrm{ss}$ Tt 3,8 ). De este modo la experiencia de la fuerza cristiana es un robustecimiento en el hombre interior $(\mathrm{Ef} 3,16)$, que le concede una valentía ( 2 Cor 4,13 ss.) y un poder para edificar siempre - no para destruir $(2$ Cor 13,10$)$ - a partir de la energía de Dios (1 Cor 12,4ss.7), de su unción (2 Cor 1,21), fruto del dinamismo de Dios (2 Cor 6,6s.), del dinamismo interior del Evangelio (2 Cor 4,7 Rm 1,16 Cl 1,11 Ef 3,7s.), donde se revela la justicia y la santidad de Dios (Rm 1,17), es decir, donde se manifiesta el mismo Cristo (Rm 16,25s.). Por eso esta fuerza, al ser de Dios, reviste unas características propias: está en vigoroso contraste con la debilidad de la carne ( 2 Cor 4,7 Ef $3,7 \mathrm{~s}$.) y tiene una dimensión cristológica, al estar ordenada como una capacidad para hacerlo todo por Cristo más allá de todo egoísmo $(2$ Cor 12,10$)$ y a gozarse en él $(2$ Cor 12,10$)$ como fruto de su gracia ( 2 Cor $12,9)$, ya que en la participación de sus trabajos apostólicos es también donde se goza de la fuerza de su Resurrección (2 Cor 13,3s. Fp 3,10s.); al mismo tiempo, mantiene esta fuerza una dimensión eclesial, al conceder al apóstol la energía que proviene de la unión con la Iglesia ( 2 Cor 1,21 ), dónde mora Cristo con su fuerza $(2$ Cor 13,5$)$ y reviste también una nota escatológica, pues posibilita la firmeza hasta el final $(1$ Cor 1,8$)$ y a esta perseverancia está fundamentalmente orientada (cf. Mc 13,13 Mt 10,22; 24,13).

La fuerza de la divinidad se hace especialmente patente en los padeci- 
mientos apostólicos en forma de aguante, pues es ahí donde se experimenta de forma vigorosa el consuelo de Dios. Ya en el A.T. al interrogante profético del hasta cuándo del desastre sucede por parte de Dios la promesa de un consuelo (Is 6,11), que alienta el ministerio profético. Particularmente a Jeremías se le promete la asistencia fortificante del Señor, que logrará el que ningún enemigo prevalezca contra el profeta $(\mathrm{Jr} 1,8 ; 15,20)$, y a Ezequiel se le exhorta a no tener miedo, aunque traten de matárselo, porque son casa de rebeldía y se le anima a seguir hablando a pesar de su innata condición de debilidad humana, pues es Dios quien se lo ordena $(\mathrm{Ez} 2,6)$. Este consuelo fortifica también al Siervo de Yahweh con la promesa de un futuro éxito de Dios (Is $53 \mathrm{Zc} \mathrm{12,10}$ cp. 2 Mc 7,38); y por ello sus dolores son como de parto con el presagio de una feliz generación (Is 66,9s Jr 30,6s Mq 4,10 cp. Jn 16,20ss.).

En el N.T. Jesús se siente interiormente animado con el ardiente deseo de ser bautizado con su pasión y de hacer arder el fuego de su ministerio (Lc 12,50); y Dios Padre le conforta con su presencia (Jn 12,27s.) y con las señales de ella (Mc 1,12s Lc 22,43). Sus discípulos, llenos de miedo en un comienzo (Jn 20,19), llegarán a sentirse felices de haber podido sufrir por su Nombre $($ He 9,16). Y Pablo en concreto dará testimonio de esta alegría plena, que él experimenta en medio de su tribulación apostólica ( 2 Cor 7,4$)$, colocando el verdadero gozo no en visiones ni revelaciones (2 Cor 12,1 cp. Lc 20,20), sino en el desgastarse por la Iglesia en una postura de continua oblación (Fp 2,17), es decir, en un participar de la cruz de Cristo, de los sufrimientos llevados a cabo para extender la realidad cristiana (Gl 6,12.14; 2 Cor 11,$30 ; 12,5)$, donde nota la asistencia del Resucitado ( 2 Cor 1,3ss. 7 Fp 3,10ss.), que le actualiza la gracia de Dios (2 Cor 8,1), y que es la que le basta para mantenerse firme en su vocación y en su misión ( $2^{\circ}$ Cor 12,9$)$. Es por aquí por donde van creciendo en él los valores cristianos de integración, como son el aguante, la esperanza y el amor $(\mathrm{Rm} 5,3)$ y donde goza profundamente, al compartir la debilidad de la Iglesia y al sentir la fuerza que posee para socorrerla (2 Cor 11,30); por eso Pablo no se acobarda cuando en algo puede ser útil a la Iglesia (He 20,20).

De esta fortaleza nace radicalmente la libertad, que es una experiencia concomitante a la de la vocación, pues Dios llama al hombre para la libertad (Gl 5,13), como liberación de todas las fuerzas del mal (Jn 8,31-36). Y esta experiencia, que fue ya la del Pueblo de Dios desde el comienzo de la vocación de su padre Abraham (Gn 12,1-4) y en los orígenes de su ser con la salida de Egipto (Ex 3,7-10), que se vio coartada solamente en el momento de su infidelidad a la vocación con la experiencia del destierro, es también la que brilla característicamente en todos los profetas y en su ministerio, como aparece en los casos ejemplares de Amós (Am 7,10-17), Jeremías (Jr 1,17ss.) y Ezequiel (Ez:2,1-7). 
También Jesús aparece como profeta, hablando con toda franqueza al mundo (Jn 18,20s cp. 7,25s), y lo hace especialmente desde el momento supremo de su entrega en el Misterio Pascual (Jn 16,25ss cp. 10,24s.), como se lo había anunciado ya a sus discípulos (Mc 8,32; 9,32; 10,32). Ellos recibirán esta misma capacidad de su Maestro (He 4,13.39), que les llevará a hablar y a enseñar con franqueza, fundados en la gracia del Señor Jesús (He 4,29s) y en la presencia de su Espíritu (He 4,31), como lo muestran Pedro ( $\mathrm{He} \mathrm{4,8),} \mathrm{Apolo}$ (He 18,25s.) y sobre todo Pablo. Es Pablo quien más expresa su experiencia interior de libertad, nacida de su referencia a Cristo el Señor (Gl 5,1s.), como gracia recibida de él a través del Evangelio $(\mathrm{Gl} 2,4)$ y que se identifica con el amor para el servicio (Gl 5,15), fruto del Espíritu y de su economía espiritual más allá de cualquier cerrazón en esquemas de carne $(2$ Cor 3,17). Esta libertad es característica de toda la existencia apostólica (Fp 1,20 Ef 3,12) y se muestra sobre todo en la valentía para la predicación del Evangelio (Ef 6,19s.). Al mismo tiempo esta libertad espiritual, que da acceso confiado a Dios (1 Jn 3,21; 5,14), es la que desde Dios, dando testimonio de su presencia en el hombre (Ef 3,12$)$, le capacita para una libertad en todas sus actuaciones humanas (Ef 6,20 cf. 1 Ts 2,2; 2 Cor 7,4; 1 Tm 3,13 cp. Fm 8); de este modo el apóstol, al encontrarse patente ante Dios, se siente también como el vivo reflejo de Cristo en todas sus actuaciones, llevadas a cabo desde la experiencia del Señor (2 Cor 3,12).

Todo esto concede al consagrado una experiencia de la gloria de la presencia de Dios en el hombre, que se adquiere por la interiorización del mensaje de Cristo. Y esto le lleva al consagrado a gozarse plenamente en esta gloria y a sentirse integrado desde Dios. El A.T. había criticado ya diversas posturas de gloria vana, de falsa integración: el menosprecio de Dios (Sl 94,3s; 74,3s Jr $12,13$ cp. Sl 3,$11 ; 25,2$ Is 13,$3 ; 23,12 ; 24,8)$ y su negación (Jc 7,2 cp 4,9 Is $50,15)$, là vaciedad humana $(\operatorname{Pr} 25,14 ; 27,1)$, la riqueza y el poder (Sl 52,3s.; 94,7 Jr 51,41 Ez 24,5; 32,42 Pr 11,7 Si 11,4), la sabiduría terrena (Jr 9,22s.) y todos los mitos idolátricos ( $\mathrm{Jr} 50,38 \mathrm{Sl} 97,7)$. La gloria es un atributo propio de Dios, es la manifestación de su ser poderoso tanto en la creación (Sl 71, 8 Is 63,12 ) como en el culto (Is 60,$7 ; 63,15 \mathrm{Sl} 78,61$ ) y en las maravillas de la historia salvífica ( $\mathrm{Sl}$ 96,3 $\mathrm{Nm} \mathrm{14,22;1} \mathrm{Cr} 16,14)$. Este Dios es el que elige a su pueblo, para que sea una realidad gloriosa en su referencia a él (Dt 26,18s. Jr 23,11 Sof 3,19 s cp. Jr 33,9 Is 43,7; 62,6; 63,14 Sl 115,1) y el mismo Dios se gloría de esta gloria suya en medio de su Pueblo (Si 17, 8ss; 24,1s. cp. Is 49,3; $60,22 ; 61,3)$. Por su parte el pueblo reconoce esta gloria en Dios (Ez 16, 12.17.39 Zc 12,7 Si 45,12; 50,11 cp. Is 4,2; 46,13 Sl 148,14), en el Mesías (Is $11,10)$, en David $(1 \mathrm{Cr} 17,8)$ y en el hombre en general $(\mathrm{Sl} 8,6 \mathrm{cp} \mathrm{21,6)}$ y hace de Dios la causa de su gloria (Dt 10,21; 33,29), como lo hace también especial- 
mente el profeta (Jr 17,14-17). Consiguientemente el pueblo se gloría en el Señor, poniendo en él la razón y el sentido de toda su existencia y de sus valores (Si 32,11; 50,20 Sl 106,47; 149,5; 1 Cr 11,35 cp. Sl 64,11; 105,2; 106,5; $1 \mathrm{Sm}$ $2,1)$; y sobre todo lo hace el mejor representante de esta espiritualidad véterotestamentaria, que es el justo (Pv 20,9), quien se gloria en el temor de Yahweh (Si 1,$11 ; 9,16 ; 10,22 ; 25,6)$ y en el cumplimiento de su voluntad (Si 31,9 ss Jc 15,9).

Para el N.T. en general, la verdadera gloria de Dios se encuentra en el hombre y más especialmente en Jesús de Nazaret, quien la transmite junto con su ser y con sus palabras (cf. Heb 2,6-9). Por esta unión de Jesús con el Padre, como su Apóstol, él nunca acepta como definitiva una gloria humana, aunque la use (Jn 5,41), ni busca la suya propia, sino la del que le ha enviado. (Jn 8,50); es así como aparece glorioso y plenamente integrado, sobre todo en el momento de su plena realización como Hombre y como Enviado a partir de su Hora (Jn 12,23; 13,31 cp. 7,6ss. cf et. 19,5.14). Es esto lo que indica todo el misterio de su Transfiguración (Mc 9,2-8pp. cp. 2 Pd 1,17 Ef 5,14 Jn 1,14).

Pablo también se siente glorioso, es decir, plenamente integrado y se alegra en ello, al sentir el dinamismo de Cristo, que le mueve en su relación para con Dios (Rm 15,17s.) a través de la sabiduría de la Cruz, interiorizada en el corazón del apóstol (1 Cor 2,7), que es la que le concede una gloria carismática, real y no aparente, y profundamente íntima, con la que ninguna otra pretensión humana de integración se puede igualar ( 2 Cor 11,9ss.). Por eso también la Iglesia se puede gloriar en el apóstol $(2$ Cor 5,12$)$ y en sus trabajos apostólicos, ya que por ella los sufre (Ef 3,13$)$. Este gloriarse en los sufrimientos apostólicos y rebosar de gozo en medio de ellos es algo de lo más característico en la primitiva espiritualidad apostólica $(\mathrm{He} 5,41)$ y sobre todo en $\mathrm{Pa}$ blo, ya que ahí se manifiesta el que tal gloria no es un gloriarse y alegrarse en la carne, sino sólo en Dios y ante él $(1$ Cor 1,29$)$ y nunca por tanto independientemente de los valores divinos (1 Cor 4,7); es, pues, un gloriarse y gozarse en el conocimiento de la voluntad del Señor ( $R \mathrm{~m} 2,17 \mathrm{~s}$.), en su práctica (cp. Rm 2,23) y en su enseñanza (cp. Rm 2,19-22).

Consiguientemente es una gloria que se posee en Cristo y en la referencia a él (Fp 3,13); por eso posee unas notas características, que le definen como tal gloria cristiana, donde aparece la razón del consuelo típicamente cristiano, distinto de cualquier otro tipo de gozo y de satisfacción. Es una gloria del que se goza en la Cruz de Cristo, es decir, en el compartir las consecuencias dolorosas de la participación en su vida y en su misión (Gl $6,12.14)$, y en la paciencia y en la fe, que brota pujante en medio de las persecuciones, que sufre la Iglesia (1 Ts 1,4s.). El apóstol se siente también íntimamente realizado, al haber podido llegar hasta la Iglesia con el mensaje de la fe $(2$ Cor 10,15$)$ y al ha- 
berlo podido predicar, participando de la pobreza de Cristo (1 Cor 9,15) e incluso en medio de sus propias debilidades, donde aparece más clara la acción de la fuerza de Dios (2. Cor 12,9 cp. Ef 3,7s.). Por eso el apóstol se gloría también por el fruto apostólico, que se ha logrado en medio de persecuciones, porque así aparece más clara la acción de Dios $(2$ Ts 1,4$)$; y se alegra además, al ver toda la buena conducta de su Iglesia ( 2 Cor 7,$14 ; 8,24)$. Más aún, mirando al futuro, el consagrado se goza en el éxito de toda su vida (2 Cor 9,2s.), que se manifestará plenamente en el día de Cristo (Fp 2,16). Pero no sólo para entonces, también ahora experimenta el gozo de la revelación del Señor a su alma (2 Cor 12,5), no por haberla tenido (cf. v. 1), aunque éste también sería un gozo válido (cf. v. 6), sino porque en esa revelación se le ha hecho patente su Señor y se alegra de conocerle más y de poder amarle mejor.

Es así como el consagrado logra el fruto definitivo de su vida, que es la salvación plena y total de todo su ser, donde encuentra todo su sentido y todo su gozo. Ya Jesús había vivido toda su misión hasta la muerte como una realidad salvífica, pues sentía que nadie le quitaba la vida, sino que él mismo la depositaba, para volverla a recobrar de nuevo (Jn 10,17 cp. 13,4.12); con un mismo acto intentaba todo el complejo de su acción pascual: la muerte y la vida. Ésta era la orden, que había recibido de su padre (Jn 10,18) y sabía que en ella y en su cumplimiento consistía la vida eterna, la vida misma de Dios (Jn 12,50), que él la poseía con la palabra de la misión (Jn 6,57). Por eso promete también a sus discípulos que quienes pierdan la vida por él y por el Evangelio la habrían de recobrar de un modo nuevo (Jn 12,25), se habrían de salvar. (Lc 17,33 cp. 18,28ss.) con una salvación, que no sólo alcanzaba al momento de la escatología, sino que era también una experiencia del aquí, del ciento por uno (Mt 19,27-30), aunque fuera en medio de persecuciones (Mc 10,29s.).

A Pablo es la alegría desinteresada en el apostolado lo que le concede la experiencia de salvación, que él la concibe como un don del Espíritu, que lo favorece también la oración de la Iglesia por él (Fp 1,19). Para Pablo, la salvación cristiana es algo que se experimenta ya aquí de algún modo, sobre todo a partir de la esperanza, basada en la fe y movida por el amor, prenda del Espíritu, que nunca engaña $(\operatorname{Rm} 8,24)$. Pero es especialmente en la experiencia del Evangelio donde se siente más íntimamente la salvación y donde el consagrado a él tiene la conciencia de encontrarse integralmente salvado, en la medida en que, participando del Evangelio y proclamándolo, se convierte él mismo en una realidad cada vez más evangélica y participa más intensamente en la Buena Nueva (1 Cor 9,23). Porque es el Evangelio el que radicalmente confiere la experiencia de la salvación; si se permanece en la entrega a él y a sus valores 
(1 Cor 15,1s.), junto con la invocación a la persona del Señor Jesús (Rm 10,13), pues para la experiencia plena de la salvación es necesaria la fe en la Resurrección de Jesús, que lleva a la confesión de su señorío ( $R m$ 10,8); de este modo el hombre aparece plenamente salvado y expresa su salvación no sólo interna, sino también externamente, pues todo su interior y exterior entran en la realidad del Señor Resucitado (Mt 24,13 Lc 7,50; 8,12.48.50; 9,24; 17,19; $18,26.42 \mathrm{He} 5,31 ; 1$ Cor 5,5 Rm 5,9s; 8,24; 10,10 Ef $2,8 \mathrm{Heb} 7,25$ cf et. Lc $1,47.69 .71 ; 2,11.30 ; 3,6 ; 19,10$ Jn 4,42; 10,9 He 4,12; 13,23; 15,11 Fp 2,12; 3,20 Ef 5,$23 ; 1$ Tm 1,$15 ; 4,20$ Tt 2,$13 ; 3,4.6$ ).

Es entonces cuando se produce la experiencia plena de la salvación, de aquella sanidad e integración, que las cartas típicamente paulinas denominan salvación y que en las cartas pastorales se califica como sanidad, a la vez que se establecen claramente sus causas: la palabra evangélica $(1 \mathrm{Tm} 6,3 ; 2 \mathrm{Tm}$ $3,15 \mathrm{cp}$ Ef 1,13) de la predicación ( $2 \mathrm{Tm} 1,13 \mathrm{cp}$. 1 Ts 2,16), incluso a partir de la necesaria argumentación cristiana ( $\mathrm{Tt}$ 1,9), y la concomitante verdadera fe y auténtica caridad, junto con el aguante que engendra (Tt 2,2). Son, pues, las virtudes típicas de la referencia a Dios, las posturas teologales, nacidas a partir del contacto con el Evangelio, las que integran totalmente al hombre en su realidad plena desde el plano de Dios y le conceden el consuelo y el gozó del sentido pleno de su vida y la experiencia de la sanidad y de la salvación, al verse plenamente integrado en todo su ser (cf. 1 Ts 5,9; 2 Ts 2,13).

Jesús LUZARRAGA

Universidad de Deusto

Bilbao 